\title{
Cancer Cluster
}

National Cancer Institute

\section{Source}

National Cancer Institute. Cancer Cluster. NCI Thesaurus. Code C19716.

A geographic area displaying a higher-than-expected rate of cancer incidence. 